\title{
Effects of Abiotic and Biotic Factors on the Snail Predator, Procambarus clarkii, Girad (Decapoda: Cambaridae): Implications for Schistosomiasis Control in Kenya
}

\author{
Maina $\mathrm{GM}^{1,4^{*}}$, Kinuthia JM ${ }^{1}$, Mutuku MW' ${ }^{1,4}$, Mwangi IN ${ }^{1}$, Ndeti $\mathrm{CM}^{4}$, Arunga GO ${ }^{3}$, \\ Agola EL ${ }^{1}$, Kutima $\mathbf{H L}^{2}$ \\ ${ }^{1}$ Centre for Biotechnology Research and Development, Kenya Medical Research Institute, Kenya \\ ${ }^{2}$ Department of Zoology, Jomo Kenyatta University College of Agriculture and Technology, Kenya \\ ${ }^{3}$ Centers for Disease Control and Prevention (CDC) \\ ${ }^{4}$ College of Health Sciences, Jomo Kenyatta University of Agriculture and Technology
}

Received: February 15, 2018; Accepted: March 21, 2018; Published: April 24, 2018

*Corresponding author: Maina GM, Centre for Biotechnology Research and Development, Kenya Medical Research Institute, College of Health Sciences, Jomo Kenyatta University of Agriculture and Technology, Nairobi, Kenya, P.O Box 54840-00200; Tel: +254720 999 586; E-mail: gmaina@ kemri.org

\section{Abstract}

Background \& Objective: There is increasing interest not only in the control of schistosomiasis but also, the physico-chemical parameters responsible for seasonal variation in transmission of the disease and the effect they may have on both the predator, crustacean, and the snails. In Africa, one of the major challenges of studying these parameters is lack of equipment that can be used in-situ. In the present study, we sought to assess the effects of physic-chemical parameters of schistosomiasis transmitting snails and their natural predators, crayfish.

Methods: Cross-sectional study design employing quantitative techniques for data and analysis collection. Study was conducted in MachakosKitui area of Kenya within the river Athi drainage basin. Study subjects include snails inhabiting the study streams.

Results: 161 snail out of 2325 total sampled snails on shedding turned out to be positive for mammalian schistosomes representing a prevalence of $6.9 \%$. The $\mathrm{pH}$, water and temperature did not vary significantly in the different streams (P-value $=0.7524$ at $P<0.05)$. Increase in water temperature showed significant positive correlations with B. pfeifferi $\left(\mathrm{r}^{2}=0.665 ; P<0.01\right)$ and B. nasutus $\left(\mathrm{r}^{2}=0.0 .665 ; P<0.05\right)$, Lymneanatalensis $\left(\mathrm{r}^{2}=0.589 ; P<0.010\right)$. The overall mean $\mathrm{pH}$ value was $7.8 \pm 0.8$ with values ranging from 7.34 in KwaMutanga River to 8.6 recorded in Kyanguli River.
\end{abstract}

Interpretation \& conclusion: While planning snail sampling and initiation of biological control strategies, abiotic and biotic factors should be borne in mind as they seem to play a key role in the success of schistosomiasis intervention, especially at the intermediate host level.

Key words: Schistosome; Crayfish Procambarus clarkia; Snails B. pfeifferi; B. africanus; Lymneanatalensis;

\section{Introduction}

The major habitats of B. pfeifferiin Kenya include canals, furrows and streams found in irrigation schemes such as Mwea irrigation [1]. Tributaries especially those feeding Lake Victoria also harbor this human parasite but those in lowland belt long the coastal Kenya don't [2]. The Kenya climate variability is thought to influence the species of Biomphalaria and the schistosome they transmit [3]. Therefore, S. mansoni could exhibit compatibility differences to its vector (B. pfeifferi) from different geographical areas. In addition, genetic variation is also possible due environmental conditions the vector is exposed to As a matter of fact, the Abiotic and biotic factors determine the survival of the parasite and studies are needed to determine their effect on
B. pfeifferi and hence S. mansoni population. According to Ebert theoretical preposition (1994), parasites should be adapted more to sympatric hosts than allopatric and hosts with discontinuous distribution results to superior parasite adaptability compared to those with continuous distribution [4].This adaptation change normally affects the efficiency of control measures applied to reduce or eliminate the parasite burden. In fact, the Abiotic and biotic factors in habitats influence parasite evolution and migration. Indeed local adaptation is predominantly affected by the time taken to respond to the changing environment $[5,6]$. For instance, studies on Kenyan S. mansoni from Central and Western Kenya have reported genetical diversity and therefore response to control measure especially using chemical control could be $[7,8]$. Furthermore, genetical diversity in S. mansoni is also contributed 
to mobile human hosts who harbor long-lived adults. In contrary, B. pfeifferi is limited to aquatic habitats which have made it strong self-fertilizer [9] and therefore genetical variability should also be less. This consideration might lead to higher compatibility or cercariae production of $S$. mansoni when exposed to sympatric compared to allopatric B. pfeifferi [7]. This study aims to explore the effect of both Abiotic and biotic effects on snail predator (Crayfish, P. clarkii) which is potential biological control of snail's particularly B. pfeifferi. There are few studies on this approach as it represents the actual conditions in the transmission sites. Most of studies are laboratory-based using field-derived snails and parasites where conditions are artificially provided and the modification greatly affects adaptation consequently affecting the control measures.

P. clarkii has a mean size of $100 \mathrm{~mm}$ and large individuals can reach a length of $200 \mathrm{~mm}[10,11]$. Sexual maturity is generally reached at 11 months [12] and seems to be dependent on water levels [13]. Life span at low altitude does not exceed 3 years but can reach 5 years in higher latitudes. P. clarkii is extremely tolerant of poor water quality [10]; Oxygen 3 PPM; alkalinity 50 PPM (in CaCO3); pH of 6.-8.5; salinity 15\% and temperature of $22-25^{\circ} \mathrm{C}$ [14]. It copes well with alternatively inundated and dry areas through burrowing. Inundation periods allow the proliferation of the macrophyte component of its diet and many of its predators are eliminated during the dry periods [15]. Several studies on schistosome prevalence have been done in Kenya and to the best of our knowledge no similar study has been done in Kyanguli and Kwamutanga streams. To determine the prevalence of schistosomes in the study area, we translocated the sampled snails to regional laboratory where analysis was done. The Abiotic measurement were taken during study visits and recorded in MS Excel for further analysis.

\section{Materials and methods \\ Ethical declaration}

The study was approved by Kenya Medical Research Institute, Scientific Steering Committee and Ethical Review Committee (SERU), The Kenya Wild Life Services, and The National Environment Management Authority. The owners of the farms that bordered the study were consulted to allow the use of their land to access the study site. Protective measures such as use of latex rubber glove, gumboots and heavy duty leather gloves were strictly adhered.

\section{Sampling of Streams}

Simple random sampling technique was used to recruit the 15 streams within the Sub-County for presence/absence of crayfish and snail abundance in Athi Rivers. Each habitat had 3 sampling stations, measuring approximately 20 meters running length and spaced 10 meters apart. All sites of sampling were considered representative of the water bodies.

\section{Snail collection}

Snails were collected at random from the single stretches of the stream sectors using scoops made from stainless steel sieves with a mesh size of $2 \times 2 \mathrm{~mm}$, supported on an iron frame and mounted on a $1.5 \mathrm{~m}$ long wooden handle. Snails were randomly sampled for 15 minutes by two trained field collectors per sector along the littoral zones, total, 45 minutes per stream. Sampling time was fixed, between 9.00 Am and $12.30 \mathrm{PM}$. Snails were transported to the regional labs in plastic bowls provided with stream water and lined with vegetation.

\section{Snail identification}

Snails were sorted out into species based on shell characteristics, using standard taxonomic identification keys [16]. The planorbids were counted in respect to species.

\section{Schistosome shedding}

The sample snails were placed in wells of 24- well plastic culture plates containing $1 \mathrm{ml}$ de-chlorinated water, and left on the bench for 2 hours in indirect sunlight to induce shedding of cercariae. The wells of the plates were then examined using a dissecting microscope. All non-shedders were returned to their respective habitats to maintain ecological stability while positive snails were taken back to Nairobi, schistosomiasis laboratory for parasite cycle maintenance and academic demonstration.

\section{Crayfish sampling}

Crayfish that had being introduced to the study streams as part of a larger study were sampled using traps bi-monthly until the study ended in March 2016. The traps were constructed of wire and covered with nylon mesh (onion bag type, mesh size $1 \times 1 \mathrm{~cm}$ ), were $45 \mathrm{~cm}$ long with a diameter of $20 \mathrm{~cm}$. During each sampling session 15 meat baited traps were tethered with a nylon string and immersed in water for $1 \mathrm{hr}$. Traps were checked after 30 min and 60 minutes. Captured crayfish were sized, sexed and counted and recorded. Crayfish could also be spotted on the edges of the river banks, other were inadvertently caught on snail scoops. Trapped crayfish were returned to the habitat.

\section{Abiotic parameters}

Water velocity (V) was measured with a Schiltknecht (Switzerland) Mini Air 2 type flow meter fitted with a $22 \mathrm{~mm}$ propeller. Water velocity was measured by immersing the propeller against water flow. Turbidity was measured by drawing water into a bowl and immersing the turbid meter for 5 minutes. Depth and velocity were taken at 4 different spots within a stretch of 30 meters and averaged.

\section{Data Storage, Management and analysis}

All data were entered into a field note book and later transferred into an excel spread sheet and statistically analyzed using SPSS version 21.0 software. Absolute counts of snails both cercaria shedding and non-shedders were done. A two dimensional Kolmogorov-Smirnov test was carried out to 


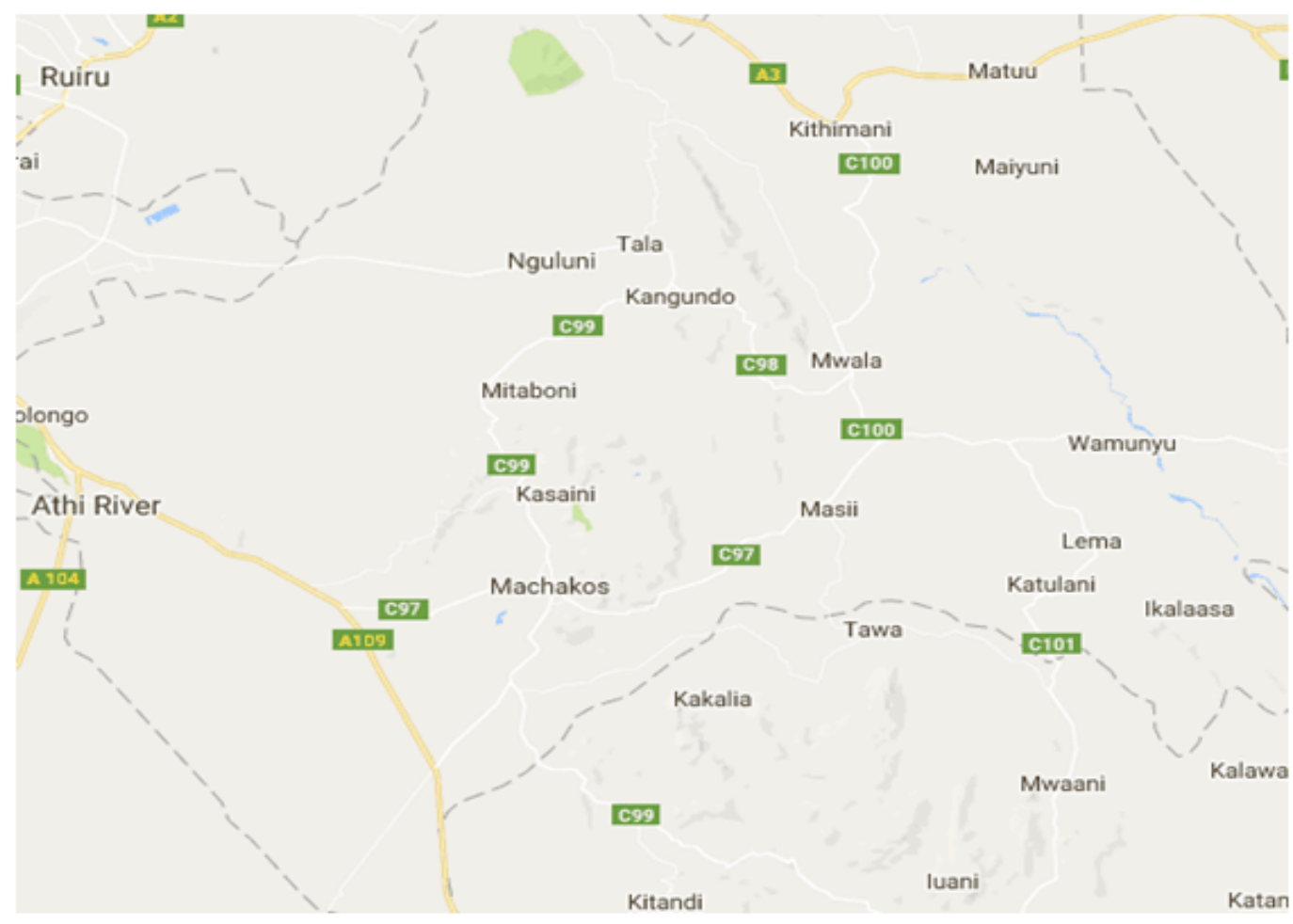

Map of Machakos showing the Athi River drainage, most of the habitats are located around Kangundo

compare the joint distribution of predator and prey to the distribution of predator and prey were independent (Fason and Franceschini, 1997).

All graphical representations were carried out using Sigma Plot 9 and graph pad. The sampling sites were mapped in the previous study using a global positioning system (GPS). New sites were mapped using a similar method and the reading imported into an Arc View version 3.3 and Arc Gis version 8.3 (Environmental Systems Research Institute, Redlands, CA). Soft copies of the data were stored on flash disks. This was to serve as a link between the field, laboratory reports and data to be entered in the computer. Data generated was kept in files which were secured in locations in KEMRI, CBRD where the principal investigator (PI) and his co-investigators were the custodian of the working documents. Generated information was stored in a computer and secured with passwords known only to the PI and his colleagues. Hard disks and removable disks were used for safe storage and backup.

\section{Results}

\section{Prevalence of mammalian schistosomes in snails from river Athi Basin}

Result indicated that out of 2325 schistosome-transmitting snails were sampled during the September 2014-March 2016 in the 4 study streams. No crayfish was found during the baseline survey. Out of the total number of snails sampled 161 on shedding turned out to be positive for mammalian schistosomes representing 6.9\% (Figure 1). The month of January 2015 had the highest number of infected snails while March 2016 had no schistosomes shedding snails.

\section{Ability of crayfish to survive and establish thriving populations in stream habitats}

During the 20 month period of the Survey 6 juvenile crayfish an indication of breeding were spotted on the edges of the experimental streams. 77 adult predators were captured in Kyanguli stream, over the entire study duration while 28 adult crayfish in KwaMutanga within the first 3 months post introduction representing a p-value of 0.002 . No crayfish was neither spotted nor trapped in the control streams. The Crayfish population went up then down and stabilized eventually as the study duration went by in both experimental streams (Figure 2).

(Figure 3) shows a decline in the population of crayfish in KwaMutanga stream while (Figure 4) shows reasonable stability of crayfish population in Kyanguli stream. This difference could be attributed to both Abiotic and biotic factors. These factors influence adaptability of the species to the environment hence regulating their population.

\section{Seasonal variation in Abiotic parameters and relationship to snail and crayfish habitation}

Several physico-chemical parameters were considered in this study which included temperature, turbidity, velocity and $\mathrm{pH}$. The water $\mathrm{pH}$ and temperature did not vary significantly in 

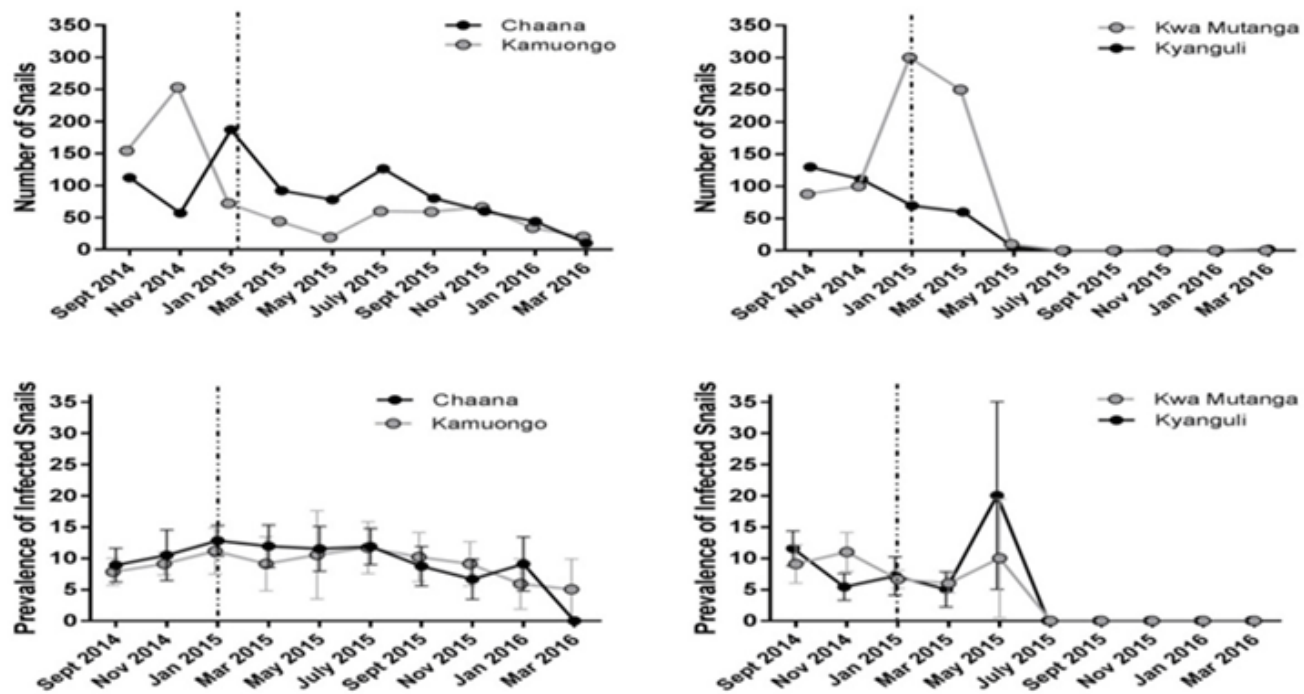

Figure 1: Prevalence of schistomiasis in snails between March 2015 and March 2016 in streams

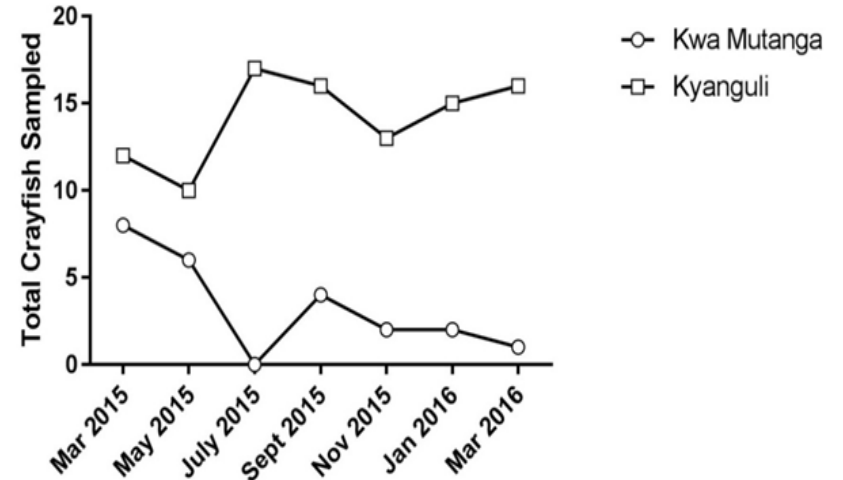

Figure 2: Total crayfish sampled between March 2015 and March 2016 in the streams

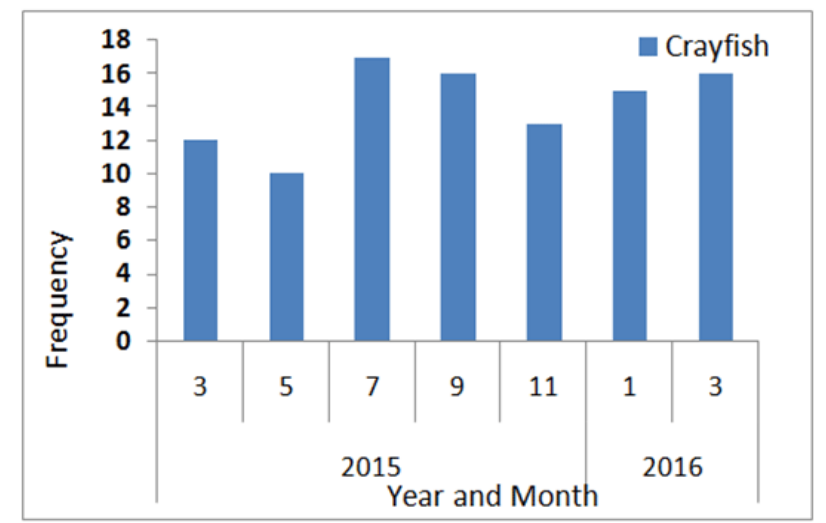

Figure 4: No. of crayfish by year \& months for the treatment group (Kyanguli)

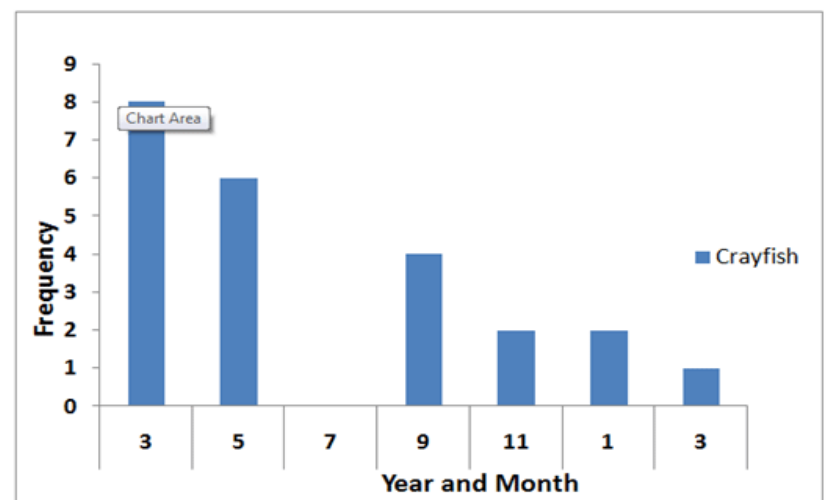

Figure 3: No. of crayfish by year \& months for the treatment group (KwaMutanga)

the different streams ( $\mathrm{p}$-value $=0.7524$ at $\mathrm{p}<0.05$ ) respectively. However, the mean water temperature values in the dry and wet seasons were $16.82 .10 \mathrm{C}$ and 25.8 OC respectively. The relationships between water temperature and snail abundance varied with different species of snails' B. pfeifferi and B. nastus (16.7\%), Lymneanatalensis 6.7\%. Increase in water temperature showed significant positive correlations with B. pfeifferi $(\mathrm{r}=$ $0.665 ; p<0.01)$ and B. nasutus $\left(\mathrm{r}^{2}=0.0 .665 ; p<0.05\right)$, L.natalensis $\left(\mathrm{r}^{2}=0.589 ; p<0.010\right)$. The overall mean $\mathrm{pH}$ value was $7.8 \pm 0.8$ with values ranging from the minimum value 7.34 recorded in Kwa Mutangastream to 8.6 recorded in Kyanguli stream. There was significant correlation in various $\mathrm{pH}$ values of the river bodies. The $\mathrm{pH}$ of the water bodies showed significant positive correlation with the abundance of B. pfeifferi $(\mathrm{r}=0.665$; $p<$ 0.05), however, the positive relationship was not significant with the abundance of $B$. ceratophalus Negative relationships 
were observed between $\mathrm{pH}$ of the following aquatic snails; $B$. ceratophalus and B. forskalii during September 2015. The overall mean value of air velocity was $1.41 \pm 4.6 \mathrm{~m} / \mathrm{s}$.

\section{Discussion}

A total of 2325 schistosome-transmitting snails were sampled of which 161 snails turned out to be positive for mammalian schistosomes showing a prevalence of $6.9 \%$. This justifies the fact that despite numerous control efforts, the estimated world prevalence of schistosomiasis has not changed over the past 50 years [17]. More than 207 million people are currently thought to be infected with schistosoma species [18]. Spartial heterogeneity in streams is a complex and evident across multiple spatial scales [19]. Stream ecosystems have very variable structures because materials are constantly moved downstream and organisms including snails and crayfish which often must re-colonize disturbed areas from refugial habitats [20]. This phenomenon was observed in Kyanguli stream where despite visible establishment of the crayfish, the population kept fluctuating with respect to rainfall intensity. Shortly after heavy rainfall, the crayfish catches dwindled, but during seasons of delayed rainfall, water velocity reduced resulting in pools of water which seemed to support reestablishment of crayfish that led to increased catches. Rivers are linear systems that change relatively predictably in discharge, water temperature, substrate size and channel size between river sections. Collectively, these changes are thought to cause large differences in biotic composition between locations along rivers [21]. Second, because rivers can have particular and distinct flow regimes discharge, its associated measures of water velocities, depths and turbulence have strong influences on stream communities [22,23]. Consequently, the geomorphological and hydrological features of catchments are often assumed to set most of the spartial scales that affect stream biota [24]. Several physico-chemical parameters were considered in this study which included temperature, turbidity, velocity and $\mathrm{pH}$. The $\mathrm{pH}$ and water temperature varied in the different streams $(\mathrm{p}=$ 0.7524 at $p<0.05$ ) respectively. The mean water temperature values in the dry and wet seasons were $16.82 .10 \mathrm{C}$ and 25.8 OC respectively. The relationships between water temperature and snail abundance varied in different species of snails' B.pfeifferi, B. nasutus (16.7\%), and L. natalensis 6.7\%. Increase in water temperature showed significant positive correlations with $B$. pfeifferi $(\mathrm{r}=0.665 ; \mathrm{p}<0.01)$ and B. nasutus $(\mathrm{r}=0.665 ; \mathrm{p}<0.05) L$. natalensis $(\mathrm{r}=0.589 ; \mathrm{p}<0.01)$. The overall mean $\mathrm{pH}$ level was 7.8 \pm 0.8 where a minimum level of 7.34 was recorded at KwaMutunga River to maximum level of 8.6 recorded at Kyanguli River. There was significant correlation in various $\mathrm{pH}$ levels of the river bodies. The $\mathrm{pH}$ of the water bodies showed significant positive correlation with the abundance of $B$. pfeifferi( $\mathrm{r}=0.665$; $\mathrm{p}<0.05)$. The positive relationship was not significant with the abundance of $B$. ceratophalus. Negative relationships were observed between $\mathrm{pH}$ of the following aquatic snails; $B$. ceratophalus, and B. forskalii. The overall mean value of air velocity was $1.41 \pm 4.6 \mathrm{~m} / \mathrm{s}$. The ecology of the snail was influenced by the physicochemical parameters of the river and its role in snail abundance was indicated in the study streams. The higher density of snails recorded in the dry season could have been due to the indirect impacts of flourishing Microflora (food supply) and aquatic macrophytes during the season. The mean $\mathrm{pH}$ levels in all the water bodies in the present study were within favorable limits for aquatic snail development [25]. The higher mean pH level recorded during the dry season could be due to higher transparency of the water bodies resulting in active removal of carbon (IV) oxide and consequently production of oxygen through photosynthesis. The concentration of hydrogen ions is rarely a factor conditioning the presence and distribution of the snails [26]. Therefore there were insignificant relationships between abundance of snails and $\mathrm{pH}$ level in our study. The main limitation of the study was that the changing environmental factors such as heavy rainfall which hindered accurate measurement of the Abiotic parameter.

\section{Conclusion}

The prevalence of schistosomes reported in this paper shows the need to initiate prevention measures in river Athi drainage system. The seasonal variation of Abiotic factor affect population of both snail and crayfish though may not be of great significance. The researchers recommend future studies to establish whether the seasonal variation affect schistosomes prevalence which may inform schistosomiasis control programs.

\section{Conflict of interest}

Authors declared no conflict of interest

\section{Acknowledgements}

Internal research grant (IRG) from the Kenya Medical Research Institute, L-1212 (Pj-611) funded this work. The community offered invaluable support in terms of accessibility.

\section{References}

1. Olsson K, Stenroth P. Nystro"m P, Graneli W. Invasions and niche width: does niche width of an introduced crayfish differ from a native crayfish? Freshwater Biol. 2009;54(8):1731-1740.

2. Loker ES, Hofkin BV, Mkoji GM, Kihara JH, Mungai FK, Mungai BN, et al. Procambarus clarkii in Kenya: Does it have a role to play in the control of schistosomiasis? In: National Research Council: Aquaculture and Schistosomiasis: Proceedings of a Network Meeting held in Manila, Philippines, August 6-10, 1991, pp 272-282. National Academy Press, Washington, DC, 1993.

3. Lowery RS, Mendes AJ. The Louisiana red swamp crayfish in Kenya. JE Afr Nat Hist Soc. 1977;9-11.

4. Ebert D. Virulence and local adaptation of a horizontally transmitted parasite. Science Journal. 1994;265(5175):1084-1086.

5. Morand S, Manning SD, Woolhouse MEJ. Parasite-host coevolution and geographic patterns of parasite infectivity and host susceptibility. Proceedings Biological Science. 1996;263(1366):119-28.

6. Prugnolle F, De Meeus T, Pointier JP, Durand P, Rognon A, The'ron A. Geographical variations in infectivity and susceptibility in the host- 
parasite system Schistosoma mansoni/Biomphalaria glabrata: no evidence for local adaptation. Parasitology. 2006;133(3):313-319.

7. Agola LE, Steinauer ML, Mburu DN, Mungai BN, Mwangi IN, Magoma GN, et al. Genetic diversity and population structure of Schistosoma mansoni within human infra populations in Mwea, central Kenya assessed by microsatellite markers. Acta Tropica. 2009;111(3):219225.

8. Agola LE, Steinauer ML, Mburu DN, Mungai BN, Mwangi IN, Magoma GN, et al. Genetic diversity and population structure of Schistosoma mansoni within human infra populations in Mwea, central Kenya assessed by microsatellite markers. Acta Tropica. 2009;111(3):219225.

9. Charbonnel N, Rasatavonjizay R, Sellin E, Brémond P, Jarne P. The influence of genetic factors and population dynamics on the mating system of the hermaphroditic freshwater snail Biomphalaria pfeifferi Oikos. 2005;108(2):283-296.

10. Arrignon JV, Huner JV, Laurent PJ. L'écrevisse Rouge des Marais Maisonneuveet Larose, Paris: 87, 1990.

11. Aragon AD, Imani RA, Blackburn VR, Cupit PM, Melman SD, Goronga $\mathrm{T}$, et al. Towards an understanding of the mechanism of action of praziquantel. Mol Biochem Parasitol. 2009;164(1):57-65.

12. Oluoch AO. Breeding biology of the Louisiana red swamp crayfish Procambarus clarkia Girard in Lake Naivasha, Kenya. Hydrobiologia 1990;208(1-2):85-92.

13. Gutiérrez-Yurrita PJ, Montes C. Bioenergetics and Phenology of reproduction of the introduced red swamp crayfish, Procambarus clarkii, in Doñana National Park, Spain, and implications for species management. Freshwater Biol. 1999;42(3):561-574.

14. Crandall KA, Buhay JE. Global diversity of crayfish (Astacidae, Cambaridae, and Parastacidae-Decapoda) in freshwater Hydrobiologia. 2008;595(1):295-301.
15. Cumberlidge N. Freshwater crabs and shrimps (Crustacea: Decapoda) of the Nile Basin. In: Dumont HJ, editor. The Nile Springer; 2009.547561.

16. Brown M, Mawa PA, Joseph S, Bukusuba J, Watera C, Whitworth JA, et al. Treatment of Schistosoma mansoni infection increases helminthspecific type 2 cytokine responses and HIV-1 loads in coinfected Ugandan adults. J Infect Dis. 2005;191(10):1648-1657.

17. Savioli L, Albonico M, Engels D, Montresor A. Progress in the prevention and control of schistosomiasis and soil-transmitted helminthiasis. Parasitol Int. 2004;53(2):103-113.

18. Chitsulo L, Engels D, Montresor A, Savioli L. The global status of schistosomiasis and its control. Acta Trop. 2000;77(1):41-51.

19. Schlosser IJ.Stream fish ecology: a land-scape perspective. BioScience. 1991;41(10):704-712.

20. Osborne LL, Wiley MJ. Influence of tributary spatial position on the structure of Warm water fish communities. CAN J FISH AQUAT SCI. 1992;49(4):671-681.

21.Vannote RL, Minshall GW, Cummins KW, Sedell JR, Cushing CE. The river continuum concept. CAN J FISH AQUAT SCI. 1980;37(1):130-137.

22.Hynes HBN. The ecology of running waters. Liverpool: Liverpool university press; 1970.

23. Allan JD. Stream ecology: Structure and function of running waters. Chapman and Hall, London; 1995:388.

24. Frissell CA, Liss WJ, Warren CE, Hurley MD. A hierarchical framework for stream habitat classification: Viewing streams in a watershed context. Environmental Management. 1986;10(2):199-214.

25. Boelee E, Laamrani H. Environmental control of schistosomiasis through Community participation in a Moroccan oasis. Trop Med Int Health. 2004;9(9):997-1004.

26. Madsen $\mathrm{H}$. Ecological studies on the intermediate host snails and the relevance to schistosomiasis control. Mem Inst Oswaldo Cruz. 1992;87(4):249-253. 